\title{
Results of research of working bodies with increased reliability of tillage and sowing machines
}

\author{
Leonid Babitskiy, Vadim Moskalevich*, and Aleksandr Belov \\ V.I. Vernadsky Crimean Federal University, Academy of Life and Environmental Sciences, 295492, \\ Russia
}

\begin{abstract}
The results of research on the influence of wear-resistant hardening surfacing on bionically justified parameters on the efficiency, durability and traction resistance of cultivator hoes and hoe coulters are presented. The economic efficiency of the proposed method of strengthening the hoe working bodies is determined.
\end{abstract}

Lancet hoe are the main working bodies of cultivators for continuous and inter-row tillage, and are also used on seeders for direct seeding. The size and shape of lancet hoes are characterized by the cone angle, angle of chopping, the grinding angle, width of wing and width. As they are used, almost all these parameters change, reducing the efficiency of the hoes. As a result of wear of the front part, the radius of the cutting edge increases, oblique cutting passes into the category of frontal cutting, which increases the resistance, breaks the uniformity of the depth of tillage and seeding. As a result of wear of the wings hoes in width occurs a discontinuity of tillage by reducing the width and the elimination of the overlap area of tillage hoes front and back rows. As the cutting edge of the blades wears out, their thickness increases, the cutting ability deteriorates and the uniformity of the depth of soil cultivation and sowing on hard areas is violated, and the traction resistance of machines increases. Forced frequent replacement of parts of working bodies reduces labor productivity and increases the cost of tillage. Therefore, the current research direction is to improve the reliability of working bodies of tillage and sowing machines in the aspect of developing ways to increase the efficiency and durability of their cutting parts. The research was carried out in accordance with the initiative research work of the Department of mechanization and technical service in the agro-industrial complex "Justification of parameters and increasing the reliability of soil working bodies on bionic and bioergonomic similarity for ecological agriculture of the Republic of Crimea", which is included in the plan of research work of the V.I. Vernadsky Federal state University, and the economic contract for the execution of scientific and technical work with PJSC Burlyuk.

Analysis of recent achievements and publications. The analysis of research results in this direction has found that as a result of intensive abrasive wear, the geometry of cutting parts and dimensional characteristics of working bodies change, which is the reason for violating agricultural requirements, reducing the quality of tillage, and increasing energy

* Corresponding author: $\underline{\text { v_moskalevich@mail.ru }}$ 
consumptions [1, 2]. In the structure of culling reasons for cultivator hoes and ploughshares, the main part is blunted blades and wear of the front part [3]. Accordingly, the main focus should be on increasing the resource of these elements [4]. At the Academy of bioresources and environmental sciences of the V.I. Vernadsky Federal state University at the Department of mechanization and technical service in the agro-industrial complex, a technology for applying wear-resistant materials to the working surfaces of parts of tillage and sowing machines with subsequent heat treatment is proposed. In this case, the blades of the working bodies are strengthened by sections according to bionically justified parameters. During operation, adjacent sections of such blades wear out at different speeds, self-sharpen and acquire a cogs shape, which contributes to the uniform depth of the working bodies in the soil and reduces the traction resistance [5].

The formulation of the goals and objectives of the work. To give a comprehensive assessment of the consequence of wear-resistant surfacing on bionically justified parameters of cultivator's hoes and seeder's hoe coulters on their wear resistance and durability, traction resistance and economic efficiency of use.

Presentation of the basic material investigations. The research is based on the hypothesis that strengthening the lancet hoes and hoe coulters with wear-resistant surfacing according to bionically justified parameters will increase their resource, reduce the consumption of surfacing materials, provide the effect of self-sharpening the blades, and reduce the traction resistance of machines.

Justification of the parameters for strengthening the hoe working bodies of cultivators and seeders was based on the study of biological prototypes - digging and cutting devices of animals and insects - in the aspect of their wear resistance and self-sharpening. Special attention was paid to the study of the structure of animal claws, which combine hard and elastic layers. This structure is explained by theoretical assumptions, according to which damage to the blade of soil-cutting parts of working bodies occurs as a result of a combination of repeated blows with the scratching action of solid soil particles on working surfaces. The most resistant to this effect is a multi-layer structure with a combination of solid elements with elastic layers. It has a maximum energy of destruction under shock stacks combined with a high resistance to abrasive wear.

Based on the above assumptions, the theoretical justification of the parameters of surfacing with wear-resistant materials was performed and a method for calculating the parameters of strengthening of cultivator hoes and hoe coulters of seeders was developed. According to the method, parameters were calculated and schemes of intermittent surfacing "by segments" and "by points" of pointed cultivator hoes, which are used on KNV-3 cultivators, and hoe coulters of the AUP sowing complex were developed. Photos of samples of working bodies are shown in Fig. 1.
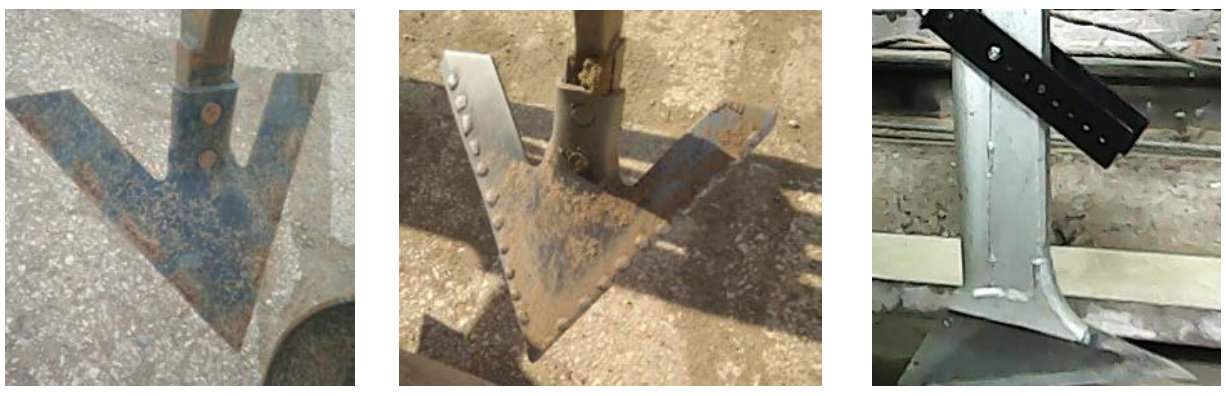

Fig. 1. Photos of samples of working bodies.

In the course of testing in production conditions, changes in the parameters of lancet cultivator hoes and hoe coulters with surfacing were recorded according to bionically 
justified parameters, in comparison with serial working bodies. When determining wear, changes in the intensity of linear wear, the configuration of the hoes and the nature of destruction of the blade surfaces were taken into account. Determination of the nature of blunting of the blades was carried out simultaneously with the determination of the loss of mass of the working organs. To assess the nature of wear of the working bodies, the thickness of the cutting edge of the blades was measured and the contour of the hoe was drawn before starting work and after a fixed operating time of the machine. Then we combined the contour of the worn-out hoe with its original contour and built a wear plot. The final evaluation of hoes with intermittent surfacing in comparison with serial claws was made by the coefficient of relative wear resistance, equal to the ratio of wear rates of serial and surfaced claws.

As a result of production tests, it was found that after processing 30 hectares of the blade of the hoe with surfacing "in sections" acquired a cogs shape. In serial hoes, after the specified operating time, there was extreme wear of the front part and blunting of the cutting edge of the blades to a thickness of $5 \mathrm{~mm}$. In this case, the thickness of the cutting edge of the blades of hoes with surfacing "in segments" does not exceed $2 \mathrm{~mm}$. Samples of arrowhead cultivator hoes with "by points" surfacing retained the arrowhead shape during the entire working life of up to 120 hectares.

The results of measurements to determine the wear of the tested lancet cultivator hoes are presented in table 1.

Table 1. The parameters of wear of cultivator hoes.

\begin{tabular}{|c|c|c|c|}
\hline Parameter & Serial hoes & $\begin{array}{c}\text { Hoes with } \\
\text { intermittent surfacing }\end{array}$ & $\begin{array}{c}\text { Percentage } \\
\text { difference in wear }\end{array}$ \\
\hline Wear by weight, g & 1295 & 990 & -23.55 \\
\hline $\begin{array}{c}\text { Linear wear, mm: } \\
\text { - front part }\end{array}$ & 86 & 25 & -70.93 \\
- blade & 68 & 46 & -32.35 \\
\hline
\end{tabular}

To determine the energy indicators of cultivator hoes and hoe coulters with increased reliability, studies were conducted in the soil channel. The comparison was carried out by the traction resistance of working bodies when buried in the soil by $8 \mathrm{~cm}$ with a humidity of $18.2-21 \%$ and a hardness of $181 \pm 2 \mathrm{~N} / \mathrm{cm}^{2}$ at a speed of $1 \mathrm{~m} / \mathrm{s}$. Data on the traction resistance of working bodies are given in table 2 .

Table 2. Traction resistance of working bodies.

\begin{tabular}{|c|c|}
\hline Working bodies & Traction resistance, N \\
\hline Hoe with intermittent surfacing of the cultivator KNV-3 & 1230 \\
\hline $\begin{array}{c}\text { Hoe with intermittent surfacing of the cultivator KNV-3 } \\
\text { after working 30 ha }\end{array}$ & 1034 \\
\hline Hoe serial of the cultivator KNV-3 & 1149 \\
\hline Hoe serial of the cultivator KNV-3 after working 30 ha & 980 \\
\hline Hoe coulter with intermittent surfacing of the AUP & 925 \\
\hline Hoe coulter serial of the AUP & \\
\hline
\end{tabular}

From a comparative analysis of the traction resistance of the studied working bodies (table 2), it follows that intermittent surfacing with wear-resistant materials of the blades at the initial stage of operation increased the traction resistance of the hoe of the cultivator 
KNV-3 and the hoe coulter of AUP, respectively, by 7\% and 5.9\%. During operation, with the same operating time of 30 ha, the traction resistance of the serial hoe of the KNV-3 cultivator increased by $14.1 \%$, and the hoes with intermittent surfacing decreased by $15.9 \%$. As a result, after cultivation of 30 ha, the traction resistance of the hoe with intermittent surfacing has a $22.7 \%$ lower traction resistance compared to the serial hoe. These data are consistent with the results of measurements of the wear parameters of cultivator hoes (table 1) and are explained by the fact that the pronged shape of intermittently deposited blades formed during operation, their self-sharpening while maintaining the overall swept shape of the hoe facilitates the process of its movement in the soil due to the concentration of contact pressures on the protrusions of the blades and less energy-intensive deformations of the soil. A rounded front part and dulling of blades serial hoes accompanied by an increase in the share of energy intensive shear deformation of the soil and, consequently, increasing its resistance.

Based on the obtained research results, the economic efficiency of the proposed method of strengthening the hoe working bodies by intermittent surfacing with wear-resistant materials according to bionically justified parameters is determined on the example of arrow-shaped cultivator hoes. The results of calculating economic indicators are shown in table 3.

Table 3. Economic indicators.

\begin{tabular}{|c|c|c|}
\hline Indicator & Basic variant & New variant \\
\hline Unit composition & \multicolumn{2}{|c|}{ T-54V+KNV-3 } \\
\hline The cost of hoes, RUR. & 12000 & 6000 \\
\hline Repair costs, RUR. & 9150 & 1860 \\
\hline The productivity of the unit, ha/h & 5.3 & 5.6 \\
\hline Specific fuel rate, kg/ha & 5.09 & 4.82 \\
\hline Salary, RUR./ha & 16.04 & 15.18 \\
\hline Specific operating costs, RUR./ha & 209.46 & 198.34 \\
\hline Given the costs, RUR./ha & 315.21 & 259.08 \\
\hline Reduced cost savings, RUR./ha & - & 56.13 \\
\hline Annual economic benefit, RUR. & - & 11226 \\
\hline
\end{tabular}

Conclusions on this research and prospects for further development of this direction. The obtained research results confirm the hypothesis about the positive effect of strengthening of pointed cultivator hoes and hoe coulters with wear-resistant surfacing according to bionically justified parameters on the reliability of tillage and sowing machines. In the process of operation, the blades of the hoe with surfacing "in segments" acquire a pronged shape, the linear wear of their wings is reduced by $32 \%$, the front part by $70 \%$, and the wear by weight is reduced by $23 \%$. In the process of tillage after cultivation of 30 ha, the traction resistance of the hoes with intermittent surfacing is reduced by $22.7 \%$ compared to the tillage with serial hoes. Since the front part of the hoe working bodies is subject to the most intensive wear, the direction of further research is to substantiate the parameters of strengthening of cultivator hoes with overhead elements. 


\section{References}

1. A.V. Ishkov, N.T. Krivochurov, et., Vestnik of Altayskiy State Agrarian University, 10, pp. 92-96 (2010)

2. V.S. Novikov, D.I. Petrovsky, Vestnik of FSEI HPE "Moscow State Agroengineering University named after V.P. Goryachkin”, v. 4 (80), pp. 49-54 (2017)

3. M.N. Yetokhin, V.S. Novikov, D.I. Petrovskiy, Sel'skiy mekhanizator, 11, pp. 6-9 (2015)

4. V.A. Kuklin, N.V. Nadopta, Current research directions of the XXI century: theory and practice, v. 2 (28), 5, pp. 55-58 (2017)

5. L. Babitskiy, V. Moskalevich, S. Mischuk, Justification of ways to increase the durability of tillage working bodies, E3S Web of Conferences, v. 126 (2019) 